\title{
ESPACIALIZAÇÃO DAS MANCHAS DE ÓLEO E GRAXA NA ZONA PORTUÁRIA DE NATAL-RN ATRAVÉS DE TÉCNICAS DE INTERPOLAÇÃO IDW E KRIGAGEM
}

\author{
J. R. SOUZA ${ }^{1}$, M. T. CAVALCANTI NETO \\ Instituto Federal de Educação, Ciência e Tecnologia do Rio Grande de Norte \\ jairo.souza@ifrn.edu.br ${ }^{1}$
}

Artigo submetido em 23/11/2019 e aceito em 11/12/2019

DOI: $10.15628 /$ holos.2019.9187

\begin{abstract}
RESUMO
As técnicas de interpolação estão sendo cada vez mais utilizadas na área das Geociências, principalmente para a espacialização de dados de plumas de contaminação no meio ambiente. Neste trabalho, tem como objetivo espacializar as manchas de óleo e graxa na zona portuária de Natal-RN através de técnicas de interpolação IDW e krigagem entre os meses de outubro e novembro de 2016. Para tanto, foram recolhidas 30 amostras d'água ao longo da zona portuária de Natal-RN no mês de outubro e mais trinta amostras no mês de novembro, totalizando em sessenta amostras d'água analisadas. Com os valores
\end{abstract}

do teor de óleo e graxa, procedeu-se a espacialização desses contaminantes através de técnicas de geoprocessamento. Verificou-se, então, que as regiões mais afetadas estavam a sul-sudeste e norte-noroeste da área de estudo e que o método de interpolação por Krigagem é mais eficiente que o IDW, uma vez que este apresentou fortes interferências do efeito "bulls eyes" ao redor de cada ponto de coleta, enquanto aquele, através da checagem do "cross validation", apresentou os Erros Médio Padronizado, Médio Quadrático, Padrão Médio e Quadrático Médio Padronizado mais compatíveis.

PALAVRAS-CHAVE: Interpolação, Teor, Zona Portuária, Natal-RN.

\section{SPATIALIZATION OF OIL AND GREASE STAINS IN THE PORT AREA OF NATAL-RN THROUGH IDW AND KRIGAGEM INTERPOLATION TECHNIQUES}

\begin{abstract}
Interpolation's techniques are being increasingly used in the area of Geosciences, mainly for the spatialization of feather data of contamination in the environment. Thus, in this work, the two IDW and Krigagem interpolation methods were compared using an oil and grease content database along the Natal-RN port area between October and November 2016. It was verified that The method of
\end{abstract}

interpolation by Krigagem is more efficient than the IDW, since this one presented strong interferences of the effect bulls eyes around each collection point, whereas that one, through the cross validation check, presented the Average Errors Standardized, Medium Quadratic, Standard and Quadratic Standardized more compatible.

KEYWORDS: Interpolation, Content, Port zona, Natal-RN. 


\section{INTRODUÇÃO}

A atividade portuária tem importância para o progresso socioeconômico de uma nação. No território brasileiro, estima-se que aproximadamente $90 \%$ do volume de cargas do nosso comércio exterior e mais de $75 \%$ do valor correspondente a esse comércio são escoados pelos portos (PAIVA et al., 2011). Apesar dos avanços promovidos pelos portos, estes acarretam temeridades que necessitam ser consideradas e reduzidos, principalmente, ao meio ambiente com derramamento acidental de óleo (PAIVA et al., 2011).

Os vazamentos de petróleo e seus derivados comumente ocorrem em meio as ações de exploração, deslocamento, estocagem e manutenção de navios, causados por falha nos aparelhamentos e no manuseio de combustíveis fósseis (NOERNBERG; LANA, 2002; SANTOS, 2015).

O Porto de Natal/RN, situado à margem direita do estuário do Rio Potengi, concentra importantes operações comerciais (dentre eles, o transporte de petróleo) e elevado tráfego diário de embarcações, também já sofreu com vazamento de óleo. No ano de 2012, por exemplo, a Capitania dos Portos identificou uma mancha de óleo nas adjacências da zona portuária de Natal$\mathrm{RN}$, que ligeiramente se deslocou até a região e empregou procedimentos de contenção de arrasto dessa contaminação (ALMEIDA, 2012). Em junho de 2016, Souza et al. (2016) também identificaram a presença desses agentes contaminantes na zona portuária numa média de 1,74 mg de óleo e graxa.

Além disso, constata-se, no seu entorno, inúmeras atividades antrópicas de ordem bastante diversificada e de forma desordenada. Consequentemente, devido à alta vulnerabilidade ambiental desse ecossistema, essas ações vêm contribuindo para a sua degradação como, por exemplo, lançamento de esgotos domésticos e industriais clandestinos ricos em teores de óleo e graxa (CUNHA, 1982; FRAZÃO, 2003).

Numa tentativa de estimar os locais de presença de óleo e graxa no estuário do Rio Potengi, foram utilizados métodos dois métodos de interpolação através de software ArcGIS 10.2 (ESRI, 2013). Eles são empregados com o intuito de aferir a variabilidade espacial de um determinado elemento, fundamentado em amostras retiradas no local de estudo (ISAAKS; SRIVASTAVA, 1989; MAZZINI; SCHETTINI, 2009).

Entre as técnicas de interpolação, sobressaem-se: Krigagem; Trend, Inverso da Distância Ponderada (IDW) e Spline. Além disso, a Geoestatística está sendo mais utilizada com frequência na área das Geociências especialmente para a espacialização de dados de plumas de contaminação no meio ambiente, conforme descritos por Magalhães et al. (2013) e Gardiman Junior et al. (2012).

Portanto, este trabalho teve como objetivo especializar as manchas de óleo e graxa na zona portuária de Natal-RN por meio de técnicas de geoprocessamento de interpolação IDW e Krigagem entre os meses de outubro e novembro do ano 2016 através do software ArcGIS 10.2. Além disso, fazer, posteriormente, uma análise comparativa entre os erros obtidos em cada técnica, testando assim a eficiência destes interpoladores.

\section{ASPECTOS FISIOGRÁFICOS DA REGIÃO DE ESTUDO}

A área de estudo está localizada no estuário do Rio Potengi, na zona leste da cidade de Natal$\mathrm{RN}$, situando-se entre as latitudes de $05^{\circ} 52^{\prime} 00^{\prime \prime}$ e $05^{\circ} 41^{\prime} 57^{\prime \prime} \mathrm{S}$ e as longitudes de $35^{\circ} 19^{\prime} 16^{\prime \prime}$ e 
$35^{\circ} 08^{\prime} 24^{\prime \prime} \mathrm{W}$ (Figura 1). $\mathrm{O}$ acesso pode ser pelo bairro da Ribeira, através do Porto de Natal, ou pelas praias urbanas do Forte e Redinha.

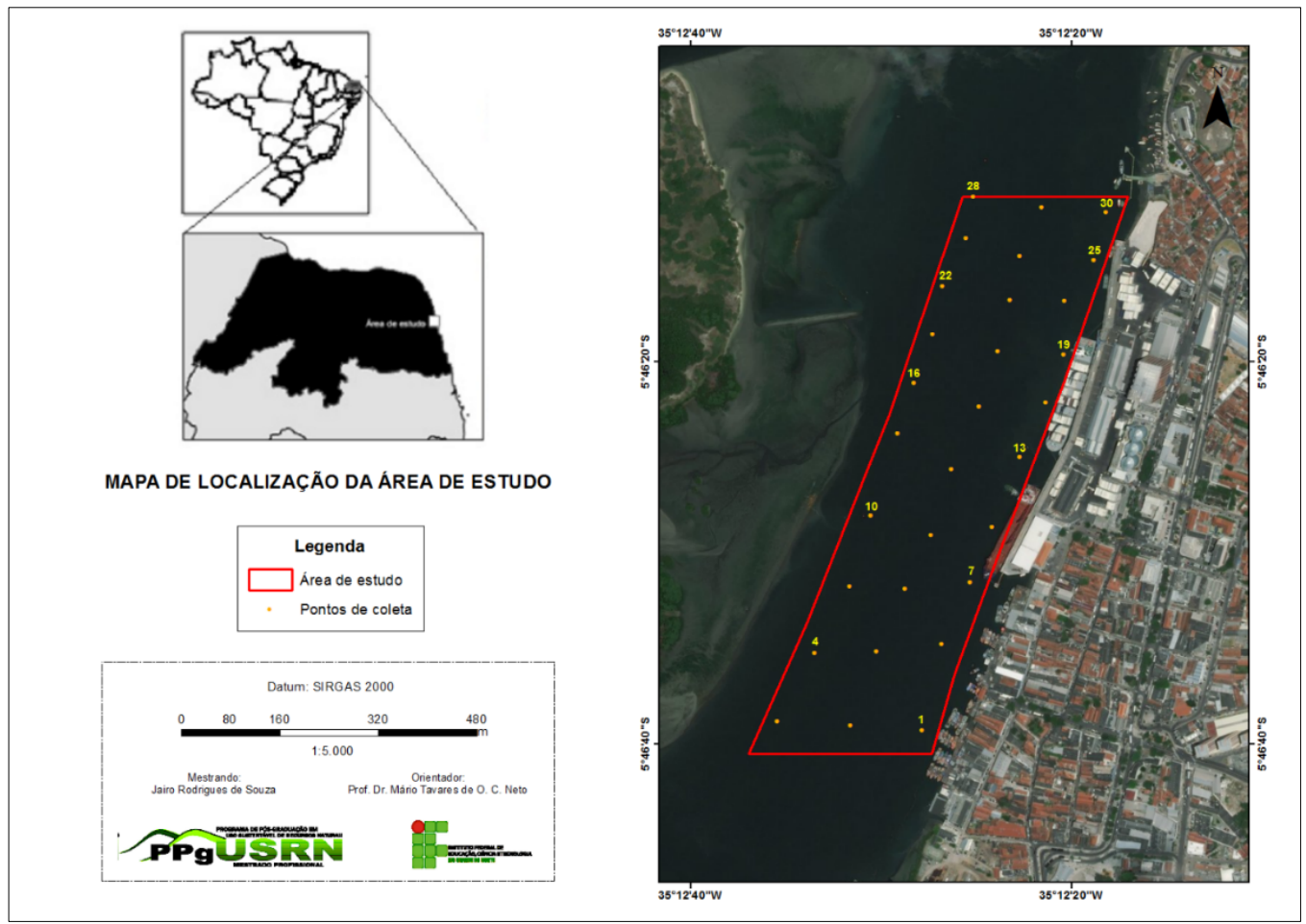

Figura 1: Mapa de localização da área de estudo com a localização de amostragem d’água

\subsection{Clima}

Conforme a classificação de Koppen, o município de Natal/RN está situado numa zona de transição entre os climas As' - quente e úmido, e BSH - árido quente, com predominância do tipo As'. O clima da região sofre interferência da Zona de Convergência Intertropical (ZCIT), onde atua nos anos em que as duas estações são bem definidas.

O período seco, de longa duração, se estende de setembro a fevereiro, devendo-se ao afastamento da ZCIT da costa em direção a norte, provocando a redução de chuvas e aparecimento de ventos mais fortes; e o período chuvoso, que ocorre de março a julho, correlaciona-se com o deslocamento da ZCIT para o sul, provocando a formação de ventos mais brandos.

A temperatura média no município de Natal/RN, no primeiro semestre de 2016, segundo os dados da Estação Meteorológica A304 do Instituto Nacional de Meteorologia localizada no Campus da UFRN, gira em torno de $27,1 \stackrel{\circ}{\circ}$, com máxima de 32 C e mínima de 23,2 으. Já a precipitação média gira em torno de $139 \mathrm{~mm}$, com máxima de $182 \mathrm{~mm}$ e mínima de $31 \mathrm{~mm}$, nos meses de maio e julho, respectivamente (INMET, 2016).

\subsection{Geomorfologia}

A morfologia da área é resultado da performance climática, sendo dominada pelos tabuleiros costeiros, que Guerra (1975) define:

Forma topográfica de terreno que se assemelha a planaltos, terminando geralmente de forma abrupta. No Nordeste do Brasil 
aparecem de modo geral em toda a costa. Paisagem de topografia plana, sedimentar e de baixa altitude (GUERRA, 1975, P.399).

Essas feições começam nas falésias costeiras e se estendem para o continente, não ultrapassando os $150 \mathrm{~m}$ de altitude nas porções mais interiores. Além disso, encontra-se a planície flúvio-marinha, onde a ação das marés, ventos, ondas, correntes e do homem representam importantes agentes modeladores deste relevo. A zona litorânea é formada por planícies de maré, com mangues associados, ao longo do estuário, praias e dunas. As regiões de baixios correspondem aos vales dos rios, ao estuário e o manguezal a ele adjacente, aos terraços fluviais e aos terraços costeiros.

\subsection{Geologia local}

Inserida na Bacia Pernambuco-Paraíba, a sub-bacia de Natal é representada, litoestratigraficamente, por rochas sedimentares mesozóicas que repousam discordantemente sobre as rochas pré-cambrianas do Embasamento Cristalino (Figura 4). Para Moreira (1996) e Fonseca et al. (1997), essas rochas sedimentares estão sobrepostas, em ordem decrescente, pelos sedimentos quaternários da Formação Potengi (pacotes maciços de arenitos avermelhados, com seixos e grânulos dispersos, não sendo observadas estruturas sedimentares primárias ou secundárias), terciário-quaternários do Grupo Barreiras (coloração avermelhada ou cinza, com grânulos e seixos de quartzo dispersos aleatoriamente em uma matriz arenosa, incialmente cimentada por óxido de ferro) e arenitos calcíferos do Cretáceo.

\subsection{Ventos}

Os ventos predominantes no litoral do Rio Grande do Norte são provenientes do quadrante $E$, seguidos dos de ESE (FRAZÃO, 2003). As maiores intensidades compreendem entre o período de julho a setembro, atingindo, respectivamente, velocidades entre 5,4 e 4,7 m/s, influenciando diretamente a propagação das ondas. Corroborando com os estudos de Frazão (2003), Ribeiro (2012) também analisou a direção e a velocidade dos ventos no ano de 2010, chegando a resultados similares. Assim, construíram-se gráficos mensais dos dados da Estação de Superfície Automática (ESA) da Estação Meteorológicas do INMET localizada no Campus da UFRN. As direções dos ventos encontradas foram de ESE a SE com velocidades médias que variam de 4,0 a 5,6 m/s, respectivamente.

\subsection{Marés}

As marés que ocorrem no estuário do Rio Potengi são denominadas semidiurnas (apresenta duas mares altas e baixas no decorrer do dia lunar, com período de maré de 12 hs e 25 min). A altura máxima gira em torno de 2,83 metros, sendo a altura média de 1,32 metros, na maré de sizígia, e 1,33 metros, no período de quadratura, refletindo um regime de mesomaré (FRAZÃO, 2003).

\subsection{Ondas}

De acordo com os estudos realizados por Cunha (2004), a costa de Natal/RN mostra ondas distribuídas principalmente nas direções $E$, cujas alturas significativas variam de 40 a 180 centímetros e períodos entre 6,4 a 8,8 segundos; ENE, cujas alturas significativas variam de 20 a 260 
centímetros e período entre 4,8 a 10,8 segundos; ESE, cujas alturas significativas variam de 40 a 260 centímetros e período entre 4,8 a 10,4 segundos.

\subsection{Hidrografia}

A área de estudo é banhada pelo estuário do Potengi, a qual se encontra influenciadas pelos riachos do Baldo, Quintas, Ouro e Prata, que recebem influência das águas subterrâneas liberadas pelos aluviões e dunas. A característica principal destes rios é que sua origem é atribuída a falhamentos geológicos. O rio Potengi nasce no município de Cerro Corá/RN, região semiárida, e segue seu curso percorrendo os relevos do Planalto da Borborema e do agreste potiguar, até desembocar em forma de estuário no oceano. Sua bacia drena aproximadamente $8,44 \%$ da superfície estadual, o que corresponde a $4.474 \mathrm{~km}^{2}$, com uma extensão de $125 \mathrm{~km}^{2}$ (IDEMA, 2003).

\subsection{Vegetação}

A vegetação predominante na área de estudo é a vegetação de mangue. A floresta de manguezal possui uma composição florística semelhante aos demais manguezais do Rio Grande do Norte, onde três das principais espécies de árvores são encontradas: a Rhizophora mangle (mangue vermelho ou mangue sapateiro) com uma grande predominância (cerca de $63 \%$ ou 546 hectares), a Laguncularia racemosa (mangue branco ou mangue manso) e a Aviecennia germinans (mangue preto) que se situam nas partes mais interiores do estuário (SEPLAN, 1986).

\section{MATERIAIS E MÉTODOS}

\subsection{MATERIAIS}

Os materiais empregados para a realização deste trabalho foram: software ArcGIS 10.2; GPS de mão do tipo Garmin Etrex e recipientes de vidro de $1 \mathrm{~L}$.

\subsection{MÉTODOS}

As atividades desenvolvidas para a elaboração deste trabalho foram subdivididas nas seguintes etapas: pré-campo (pesquisa bibliográfica, definição da área de estudo e recolhimento de trinta frascos para o acondicionamento da água), campo (amostragem d'água) e pós-campo (integração de dados em ambiente GIS).

\subsubsection{Etapa Pré-Campo}

Nesta fase, procedeu o levantamento das publicações relacionadas aos aspectos físicos da área de estudo, os principais conceitos que embasaram o referencial teórico deste trabalho e as metodologias que foram utilizadas nas diferentes etapas desta pesquisa. Assim, foram consultadas dissertações, teses, páginas eletrônicas da Coordenação de Aperfeiçoamento de Pessoal de Nível Superior (CAPES), Scientific Electronic Library Online (SciELO) e relatórios de graduação, periódicos e livros especializados. Além disso, foi definida a área de estudo no entorno do porto de Natal-RN, 
uma vez que tem um alto fluxo de embarcações propícias a derramamento ou vazamento de óleo além de conter esgotos clandestinos desaguando no rio Potengi.

\subsubsection{Etapa de Campo}

Os trabalhos de campo foram executados em duas etapas: (1) recolhimento de trinta amostras d'água colhidas na parte superficial da coluna hídrica no estuário do Rio Potengi em recipientes de vidro de $1 \mathrm{~L}$. Essas amostras foram recolhidas em regiões específicas determinadas durante o pré-mapeamento durante a etapa inicial de geoprocessamento. Por último, foram realizados (2) registros fotográficos da área de estudo no estuário do Rio Potengi e das embarcações atracadas no Porto de Natal/RN.

\subsubsection{Etapa Pós-Campo}

As amostras d'água recolhidas foram enviadas para o Núcleo de Análises de Água, Alimentos e Efluentes do Instituto Federal do Rio Grande do Norte (NAAE/IFRN) com o intuito de confirmar a presença de óleo/graxa. A metodologia empregada foi descrita por Apha (2012), utilizando os seguintes aparelhos: um tubo de óleo flutuante devidamente higienizado e um balão cônico de 300 $\mathrm{mL}$. Como reagentes foram utilizados: 1,1,2 - tricloro - 1,2,2- trifluoretano, ácido clorídrico e papel de filtro.

Posteriormente, foram adotados os seguintes procedimentos:

Flotação: Colocaram-se as amostras em tubos na posição vertical por um período de flotação de trinta minutos; no final do período de flotação, descarregou-se a água através da torneira inferior, parando antes que o óleo escape; com a água residual misturada com óleo, agita-se o tubo sobre o eixo vertical para desalojar o óleo situado no fundo e na parede do tubo. Depois, a mistura resultante ficou descansando por mais cinco minutos e, no final do período de descanso, novamente foi retirada a água através da torneira inferior, parando antes que o óleo escape.

Extração: Adicionam-se, ao tubo e a pH 2 ou inferior, cinco gotas de $\mathrm{HCl}$ e $50 \mathrm{~mL}$ de triclorotrifluoretano, respectivamente, e agitou-se a solução; com o papel filtro, filtrou-se a solução e colocou-se o líquido resultante no balão cônico de $300 \mathrm{~mL}$; adicionou uma porção de $50 \mathrm{~mL}$ de triclorotrifluoretano no líquido resultante no balão cônico de $300 \mathrm{~mL}$; evaporou-se o solvente de cada balão e, em seguida, foi determinado o peso do resíduo deixado após o processo de evaporação a partir do mesmo volume que foi utilizado na análise.

Cálculo: Para determinar o teor de óleo e graxas nas amostras, foi utilizada a seguinte fórmula matemática:

Teor $=(\mathrm{A}-\mathrm{B}) \times 1000 / \mathrm{V}$

$A$ = ganho total de peso do frasco tarado em $\mathrm{mg}$;

$\mathrm{B}$ = resíduo calculado em $\mathrm{mg}$;

$\mathrm{V}=$ volume da amostra em $\mathrm{mL}$.

Com os valores de teor de óleo e graxa adquiridos, procederam-se as técnicas de geoprocessamento para fazer a espacialização das manchas de óleo e graxa na área de estudo. As técnicas de interpolação pelo Inverso da Distância Ponderada (IDW) e Krigagem Esférica foram realizadas por meio dos valores dos teores de óleo e graxa presentes nas trintas amostras d'águas recolhidas no estuário do Rio Potengi, utilizando-se, para tanto, o software ArcGIS 10.2 (ESRI, 2013). 
De posse dos dados interpolados, procedeu-se a avaliação dos interpoladores por meio dos índices estatísticos: Erro Médio Quadrático (EMQ), Erro Médio Padronizado (EMP), Erro Padrão Médio (EPM) e Erro Quadrático Médio Padronizado (EQMP). Assim, aquele método que apresentar o EMQ mais baixo possível, EMP próximo de zero, EPM similar ou próximo ao EMQ e EQMP próximo de 1 consagrará um bom espacializador dos teores de óleo e graxa na área de estudo (LOURENÇO, 1998).

Após efetuar as interpolações, elaboraram-se mapas de interpolação para cada um dos métodos analisados, visando compará-los. Não foram calculados índices estatísticos para os valores interpolados, procedendo-se apenas uma análise visual dos mapas gerados.

\section{RESULTADOS E DISCUSSÕES}

Ao todo, durante a etapa de campo, foram feitas duas campanhas de recolhimento de amostras d'água no estuário do Rio Potengi com a intensão de comparar os teores de óleo e graxa, mapear e interpolar os resultados encontrados em ambas as expedições. Esses recolhimentos procederam-se em momentos de maré baixa ou baixa-mar, ou seja, quando a água do mar estava na sua altura mais baixa, dentro do ciclo das marés, deslocando-se exorreicamente. Uma vez recolhidas, as amostras foram encaminhadas para o Núcleo de Análises de Água do Instituto Federal do Rio Grande do Norte (NAAE/IFRN) a fim de proceder os testes laboratoriais com o intuito de verificar os teores de óleo e graxa, utilizando-se a metodologia descrita por Apha (2012). A tabela 1 mostra os valores dos teores de óleo e graxa encontrados nos respectivos ensaios:

Tabela 1: Resultados dos teores de óleo e graxa RESULTADOS DOS TESTES LABORATORIAIS

\begin{tabular}{|c|c|c|c|c|c|c|c|}
\hline \multicolumn{8}{|c|}{ TEORES (mg/L) } \\
\hline \multicolumn{4}{|c|}{ CAMPANHA 01} & \multicolumn{4}{|c|}{ CAMPANHA 02} \\
\hline AMOSTRS & $\begin{array}{c}11 / 10 / 2016 \\
\text { às 07:15 }\end{array}$ & AMOSTRAS & $\begin{array}{c}11 / 10 / 2016 \\
\text { às 07:15 }\end{array}$ & AMOSTRAS & $\begin{array}{l}\text { 08/11/2016 } \\
\text { às 16:30 }\end{array}$ & AMOSTRAS & $\begin{array}{c}08 / 11 / 2016 \\
\text { às } 16: 30\end{array}$ \\
\hline 1 & 2,19 & 16 & 1,89 & 1 & 1,03 & 16 & 0,59 \\
\hline 2 & 1,87 & 17 & 1,75 & 2 & 1,64 & 17 & 1,44 \\
\hline 3 & 1,93 & 18 & 1,76 & 3 & 2,17 & 18 & 1,23 \\
\hline 4 & 1,67 & 19 & 1,36 & 4 & 1,73 & 19 & 0,77 \\
\hline 5 & 1,6 & 20 & 1,54 & 5 & 1,55 & 20 & 0,63 \\
\hline 6 & 1,9 & 21 & 2 & 6 & 0,76 & 21 & 1,08 \\
\hline 7 & 1,8 & 22 & 2,25 & 7 & 0,68 & 22 & 0,8 \\
\hline 8 & 1,7 & 23 & 1,81 & 8 & 1,33 & 23 & 0,67 \\
\hline 9 & 1,79 & 24 & 1,83 & 9 & 0,66 & 24 & 0,78 \\
\hline 10 & 1,72 & 25 & 1,77 & 10 & 1,2 & 25 & 0,76 \\
\hline 11 & 1,78 & 26 & 2 & 11 & 0,96 & 26 & 0,54 \\
\hline 12 & 1,93 & 27 & 1,64 & 12 & 1,15 & 27 & 0,59 \\
\hline 13 & 1,7 & 28 & 1,84 & 13 & 0,72 & 28 & 0,7 \\
\hline 14 & 1,86 & 29 & 1,73 & 14 & 1,36 & 29 & 0,6 \\
\hline 15 & 2,03 & 30 & 1,76 & 15 & 0,74 & 30 & 0,71 \\
\hline
\end{tabular}

Com os teores de óleo e graxa acima, procedeu-se o mapeamento desses dados utilizando o software ArcGIS 10.2 (ESRI, 2013). Assim, foi possível definir quais locais apresentam mais ou menos a presença de óleo e graxa (Figura 2).

a. 


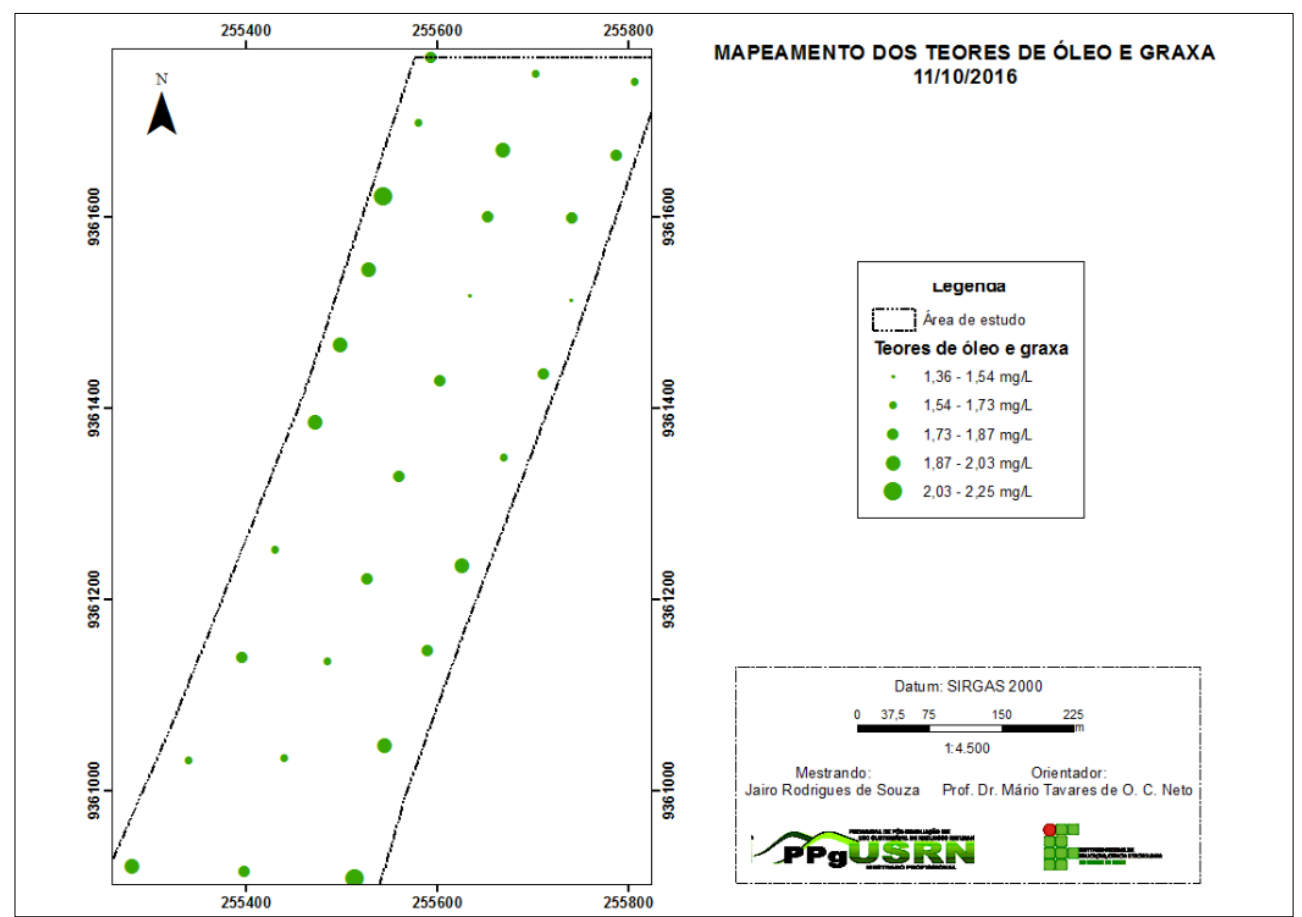

b.

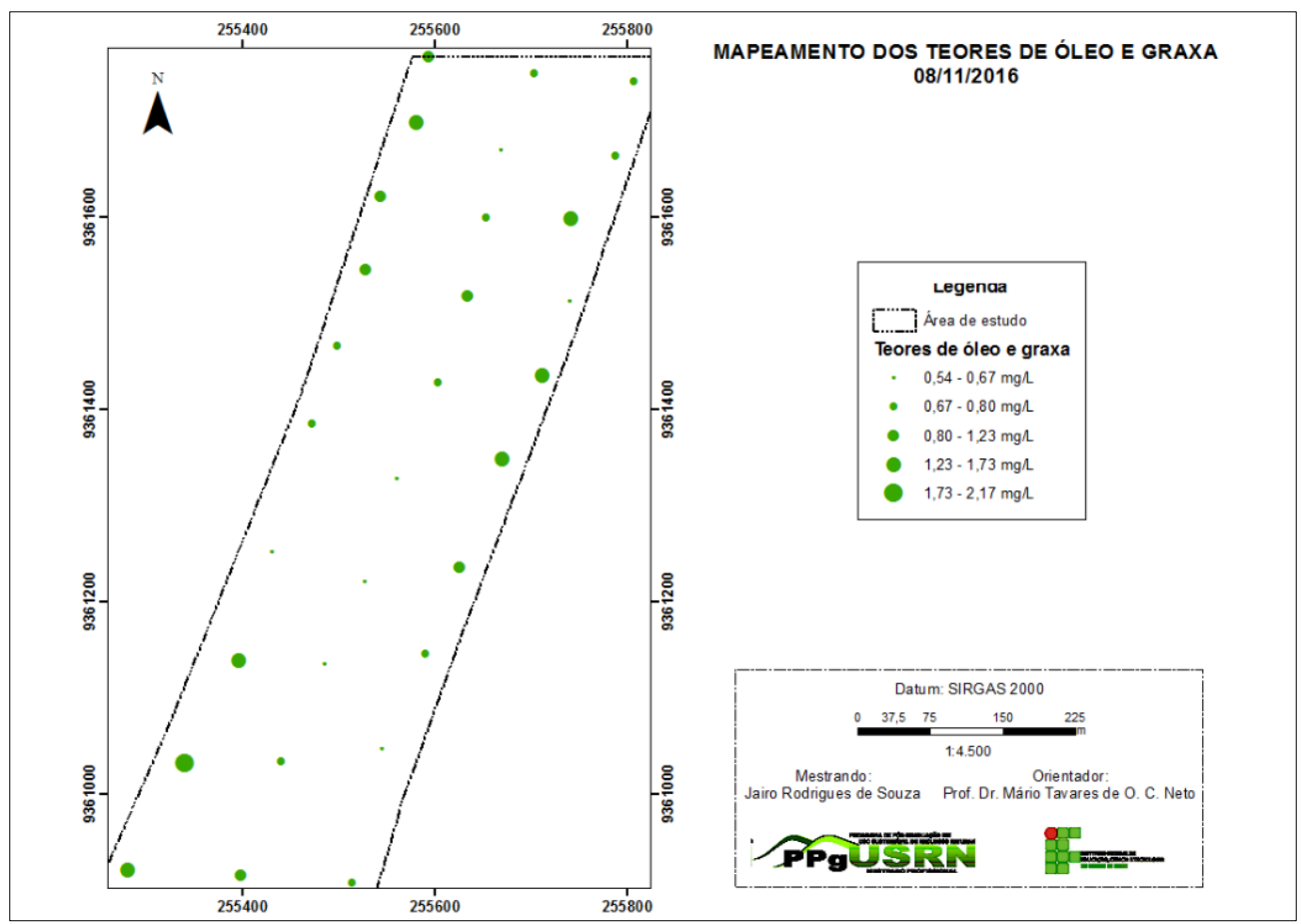

Figura 2: Mapeamento dos locais com óleo e graxa na zona portuária de Natal-RN para os dois dias de recolhimento de amostras, ou seja, (a) 11/10/2016 e (b) 08/11/2016

Ao fazer uma análise multitemporal dos mapas acima, percebe-se, na figura 2(a), que a pluma de contaminação se deslocou de sudeste a noroeste da área de estudo. Além disso, é no setor meridional que se concentra maiores teores de óleo e graxa, devendo-se a maior concentração de embarcações à combustão de pequeno e médio porte bem como se presencia local de emissão de esgoto diretamente no rio Potengi sem tratamento. Já na porção setentrional, de acordo com a 
figura 2(b), a pluma de contaminação posicionou-se a direita. O motivo dessa migração, deve-se, provavelmente, a presença de navios atracados além da dinâmica hídrica.

Posteriormente, foram realizados os processos de interpolação, os quais foram utilizados como forma de mostrar uma visualização das zonas contaminadas com maior ou menor escala. A interpolação estima o valor de uma informação em regiões donde não foram retiradas amostras, a partir de pontos amostrados numa mesma área, produzindo superfícies espaciais de interpretação. Como o cálculo da interpolação leva em consideração a média das distâncias pelos valores amostrados, os valores dos dados/atributos tendem a ser iguais ou similares em pontos mais pertos do que em locais mais afastados (CÂMARA; MEDEIROS, 1998).

Se o objetivo do estudo é indicar os locais com concentrações de óleo e graxa, as figuras 3 e 4 mostraram que qualquer destas técnicas de interpolação podem ser empregadas. Os mapas gerados seriam basicamente o mesmo, apenas com áreas mais suavizadas ou com um maior detalhamento de informações. Os dados de teores de óleo e graxa para a região do porto de Natal, interpolados pelos métodos de Krigagem Esférica e IDW estão detalhados abaixo (Figura 3, 4): a.

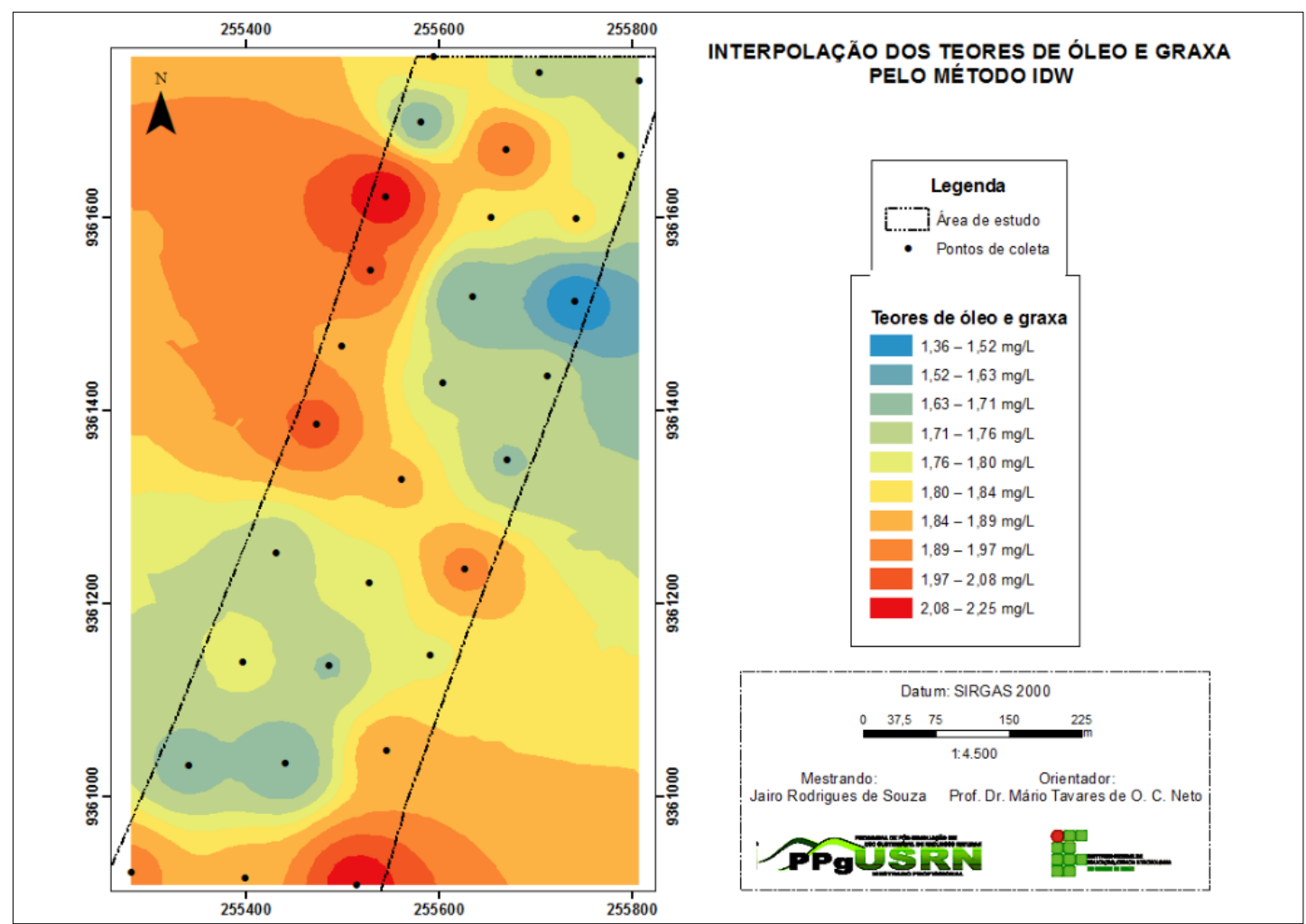


b.

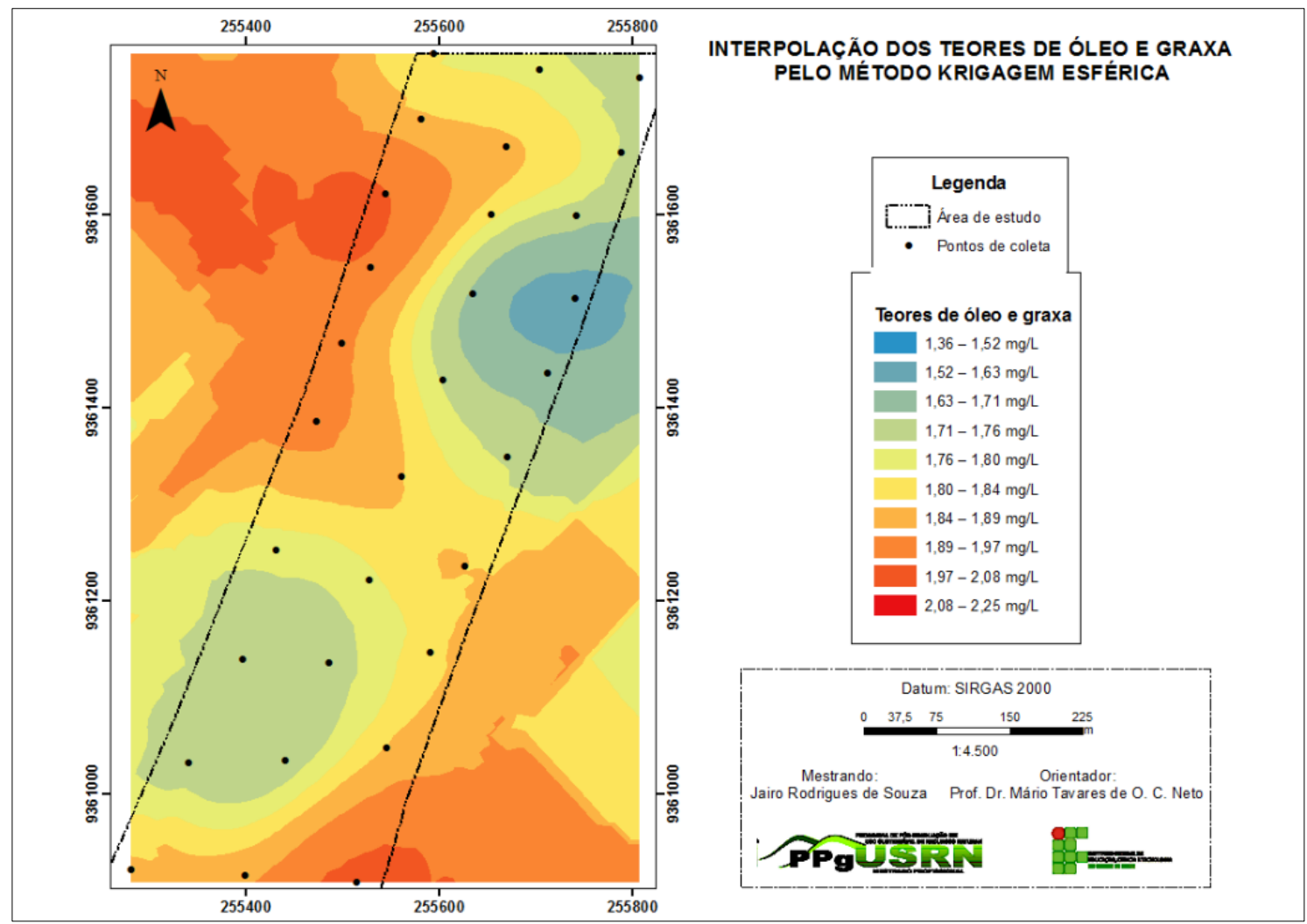

Figura 3: Mapas de teores de óleo e graxa, provenientes da interpolação de (a) IDW e Krigagem Esférica para o dia (a) 11 de outubro de 2016.

c.

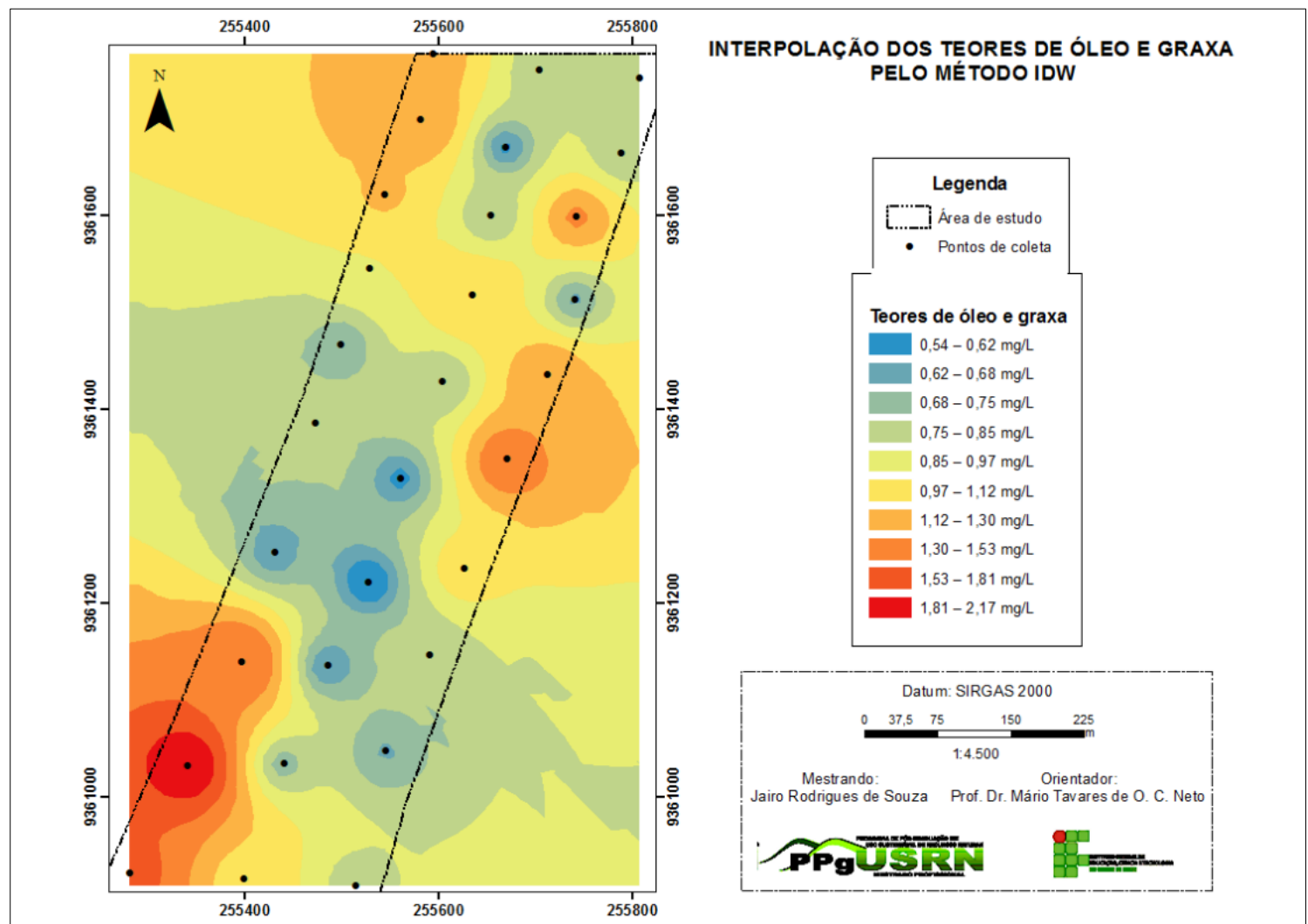


d.

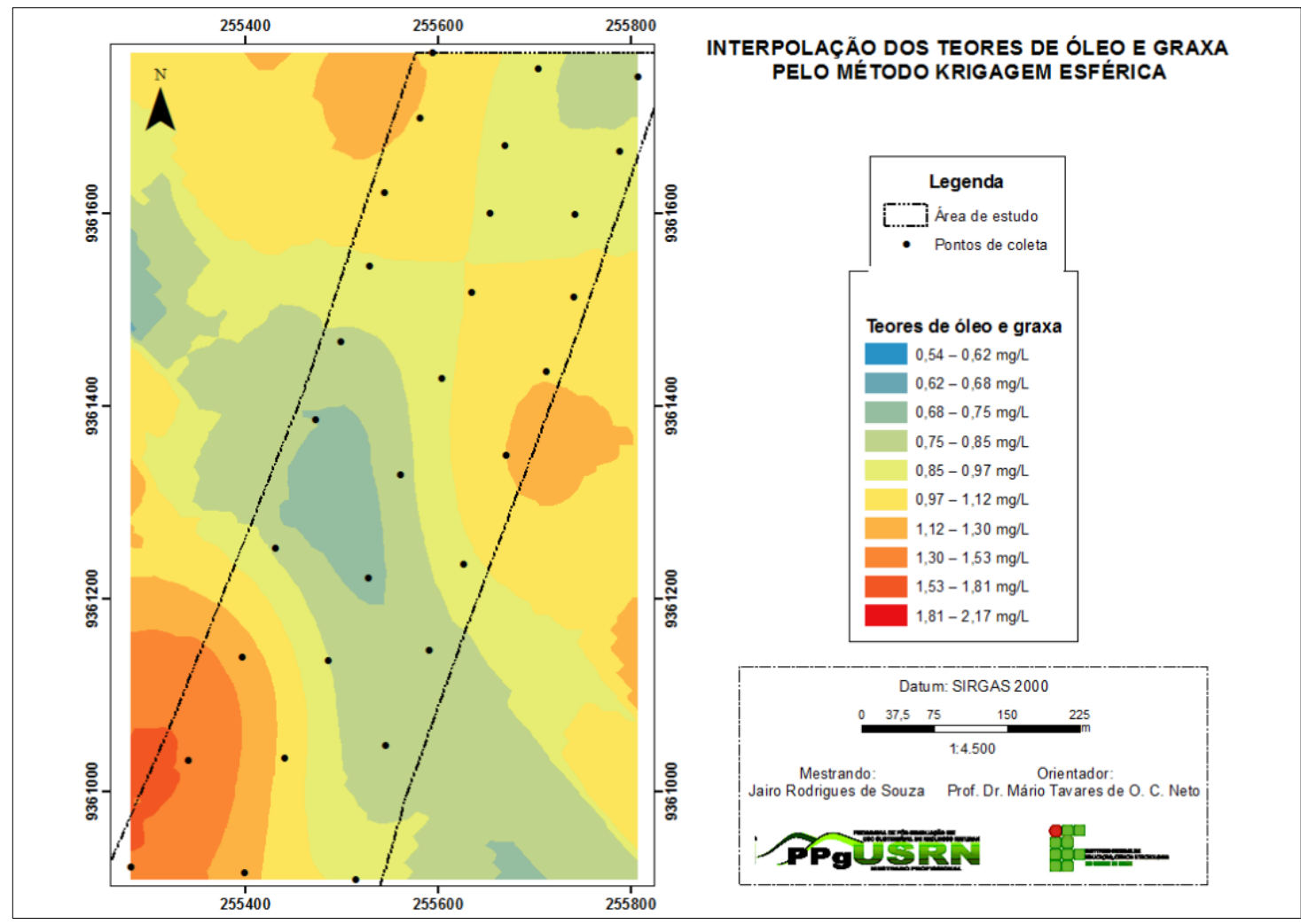

Figura 4: Mapas de teores de óleo e graxa, provenientes da interpolação de (c) IDW e (d) Krigagem Esférica para o dia 08 de novembro de 2016.

As interpolações foram utilizadas como forma de mostrar uma visualização dos resultados. Se o objetivo do estudo é indicar os locais com concentrações de óleo e graxa, as figuras 3 e 4 mostram que qualquer destas técnicas de interpolação podem ser empregadas. Os mapas gerados seriam basicamente o mesmo, apenas com áreas mais suavizadas ou com um maior detalhamento de informações. Além disso, com relação as Figura 2(a) e 3(c), notam-se que os mapas de IDW sofrem fortes interferências do efeito "bulls eyes" (ISAAKS; SRIVASTAVA, 1989) ao redor de cada ponto de coleta. Já os mapas de Krigagem Esférica traduzem uma representação mais suave e fiel do que está sendo visto em campo.

Para avaliar a técnica de interpolação mais representativa a realidade e com um maior embasamento estatístico determinístico, foi preciso analisar os erros para os valores preditos. A krigagem permitiu fazer uma validação cruzada para checagem dos dados, ou pelo menos uma comparação entre os erros (Lourenço, 1998). O ideal seria ter um erro médio padronizado (Mean Standardized) dos valores preditos próximo de "0", um erro quadrático médio (Root-Mean-Square) o mais baixo possível, um erro padrão médio (Average Standard Error) próximo do erro quadrático médio, e um erro quadrático médio padronizado (Root-Mean-Square Standardized) próximo de "1".

No caso do interpolador IDW, somente forneceu o erro quadrático médio (Tabela 2) e este tem que ser o mais baixo possível. Diante dessa particularidade, o IDW é apontado como o método geoestatístico mais simples e sem validações (LOURENÇO, 1998; CHILDS, 2004). A Tabela 2 traz os erros associados aos valores preditos destes métodos de interpolação utilizados neste trabalho.

Tabela 2: Dados dos erros dos interpoladores utilizados. 
AVALIAÇÃO DOS INTERPOLADORES

\begin{tabular}{|c|c|c|c|c|c|}
\hline \multirow{2}{*}{\multicolumn{2}{|c|}{ INTERPOLADORES }} & \multicolumn{4}{|c|}{ ERROS } \\
\hline & & E.M.P. & E.M.Q. & E.P.M. & E.Q.M.P. \\
\hline \multirow{2}{*}{$11 / 10 / 2016$} & IDW & $\ldots$ & 0,1780541 & ... & $\ldots$ \\
\hline & KRIGAGEM & $-0,03750098$ & 0,1814511 & 0,181873 & 0,9987613 \\
\hline \multirow{2}{*}{$08 / 11 / 2016$} & IDW & $\ldots$. & 0,3956755 & $\ldots$ & $\ldots$ \\
\hline & KRIGAGEM & $-0,02193325$ & 0,3783169 & 0,3853768 & 0,985297 \\
\hline
\end{tabular}

\section{CONCLUSÃO}

Nas condições em que o estudo foi realizado, a análise dos resultados permitiu-se apresentar as seguintes conclusões: o interpolador IDW admitiu apenas o conhecimento do Erro Médio Quadrático (EMQ), enquanto que a Krigagem, além desta informação, permitiu verificar também os Erros Médio Padronizado (EMP), Padrão Médio (EPM) e Quadrático Médio Padronizado (EQMP). Assim, como obteve resultados mais consistentes, a Krigagem tornou-se a técnica mais eficiência para espacialização de óleo e graxa na zona portuária de Natal-RN.

O interpolador Krigagem leva em sua análise a validação cruzada, permitindo uma representação mais fiel da superfície estudada, enquanto que o IDW sofreu forte influência do efeito "bulls eyes" ao redor da localização de cada ponto amostrado. Para que essa técnica tivesse uma validação mais perfeita, os pontos amostrados teriam que está rigorosamente distribuído de forma igualitária na área de estudo. Quanto as prováveis fontes de distribuição de óleo e graxa na zona portuária de Natal-RN temos: Efluente líquido proveniente da lavagem das embarcações e lançamento de esgotos por bueiros clandestinos. Então, necessita-se fazer novos estudos para saber a composição desses compostos para saber a real origem.

\section{REFERÊNCIAS}

ALMEIDA, R. G. Marinha detecta derramamento de óleo no Porto de Natal. Ponto de Vista, v.1, n.1, abr. 2012. Disponível em < http://www.pontodevistaonline.com.br/marinha-detectaderramamento-de-oleo-porto-de-natal/>. Acesso em: 01 de jan. 2017.

APHA, A. Standard methods for the examination of water and wastewater. 22 Edition. New York: American Public Health Association, 245 p., 2012.

CHILDS, C. Interpolating surfaces in ArcGIS Spatial Analyst. New York: ArcUser ESRI, 4 p. 2004.

CUNHA, E. M. S. Caracterização e Planejamento Ambiental do Estuário Potengi. Porto Alegre, 1982. 211 p. Dissertação (Mestrado em Geociências) - Universidade Federal do Rio Grande do Sul.

CUNHA, E. M. S. Evolução atual do litoral de Natal-RN (Brasil) e suas aplicações a gestão integrada. 2004. 393 p. Tese (Doutorado em Ciências do Mar) - Universidade de Barcelona, Barcelona. 
ESRI. ArcGIS: mapping and analysis for understanding our world (online). 2013. Disponível em: < http://www.esri.com/software/arcgis>. Acesso em: 12 de dez. 2016.

FONSECA, V. P.; BEZERRA, F. H. R; AMARAL, R. F.; AMARO, V. E. Mapeamento geológicogeomorfológico (1:250.000) do litoral oriental do Estado do Rio Grande do Norte: Primeiros Resultados. In: SIMPÓSIO DE GEOLOGIA DO NORDESTE, 8, 1997, Fortaleza. Resumo expandido...Natal: Universidade Federal do Rio Grande do Norte, 1997, p.378-382.

FRAZÃO, E. P. Caracterização hidrodinâmica e morfosedimentar do estuário Potengi e áreas adjacentes: subsídios para controle e recuperação ambiental no caso de derrames de hidrocarboneto. Natal, 2003. 197 p. Dissertação (Mestrado em Geodinâmica e Geofísica) Universidade Federal do Rio Grande do Norte.

GARDIMAN JUNIOR, B. S.; MAGALHÃES, I. A. L.; FREITAS, C. C. A.; CECÍLIO, R. A. Análise de técnicas de interpolação para espacialização da precipitação pluvial na bacia do rio Itapemirim (ES). Revista Ambiência, v. 8, n. 1, p. 61- 71, 2012.

GUERRA, A. T. Dicionário geológico-geomorfológico. 4. ed. Rio de Janeiro: Instituto Brasileiro de Geografia e Estatística (IBGE), 1975.

IDEMA, Instituto de Defesa do Meio Ambiente do Rio Grande do Norte. Diagnóstico e vulnerabilidade ambiental dos estuários do litoral oriental do RN. Natal-RN, 2003. p.51. INMET, Instituto Nacional de Meteorologia. Estações A304 - NATAL. Disponível em: < http://www.inmet.gov.br/portal/index.php?r=home/page\&page=rede_estacoes_auto_graf $>$, Acesso em: 30 de jul. 2016.

ISAAKS, E. H. \& SRIVASTAVA, R. M. An introduction to applied geostatistics. New York: Oxford University Press, 561 p., 1989.

SOUZA, J.R.; OLIVEIRA, A.K.C.; REGO, S.M.C.; OLIVEIRA, M.T. Geoprocessamento e análises químicas nas águas do Rio Potengi (Natal-RN) para avaliação de contaminações por petróleo. In: CONGRESSO INTERNACIONAL DA DIVERSIDADE DO SEMIÁRIDO, 1, 2016, Campina Grande, Artigo...Natal: Instituto Federal do Rio Grande do Norte, 2016, p. 1-5.

LOURENÇO, R.W. Comparação entre métodos de interpolação para Sistemas de Informações Geográficas. Rio Claro, 1998. 163 p. Dissertação (Mestrado em Geociências) - Universidade Estadual Paulista.

MAGALHÃES, I. A. L.; ALMEIDA, K. L.; THIAGO, C. R. L.; GARDIMAN JUNIOR, B. S.; ZANETTI, S. S.; CECILIO, R. A. Análise de métodos de interpolação para espacialização da precipitação pluvial na região Norte do estado do Espírito Santo, Brasil. In: SIMPÓSIO BRASILEIRO DE SENSORIAMENTO REMOTO, 16, 2013, Foz do Iguaçu. Artigo...Vitória: Universidade Federal do Espírito Santo, 2013, p. 5651-5657.

MAZZINI, P.L.F. \& SCHETTINI, C.A.F. Avaliação de metodologias de interpolação espacial aplicadas a dados hidrográficos costeiros quase-sinóticos. Brazilian Journal of Aquatic Science and Technology, v. 13, n. 1, p. 53-64, 2009. 
MOREIRA, M. M. Mapeamento geotécnico do município de Natal-RN. Brasília, 1996. 148 p.

Dissertação (Mestrado em Engenharia Civil) - Universidade de Brasília, Brasília.

NOERNBERG, M. A. \& LANA, P. C. A sensibilidade de manguezais e marismas a impactos por óleo: fato ou mito? Uma ferramenta para a avaliação da vulnerabilidade de sistemas costeiros a derrames de óleo. Revista Geografares, v. 5, n. 3, p. 101-122, 2002.

PAIVA, G. C.; et al. Contingências Portuárias. Brasília: Agência Nacional de Transportes Aquaviários, 452 p., 2011.

RIBEIRO, A. A. Simulações da ação do vento e da dispersão de contaminantes no estuário do Rio Potengi/Brasil. Natal, 2012. 131 p. Dissertação (Mestrado em Engenharia Sanitária) Universidade Federal do Rio Grande do Norte.

SANTOS, J. O. Relações entre fragilidade ambiental e vulnerabilidade social na susceptibilidade aos riscos. Revista Mercator, v. 14, n. 2, p. 75-90, 2015.

SEPLAN, Secretaria de Planejamento do Rio Grande do Norte. Caracterização e mapeamento dos manguezais do Rio Potengi. Natal-RN, 1986. p.67. 